\title{
Editorial: The Scholar's Degree, The Prize for the English Essay
}

There are many occasions on which plain speaking is a pleasure as well as a duty. If the speaker occupies a pulpit, literal or figurative, the pleasure may amount to a delicious self-indulgence. J. L. H. Thomas relishes such an opportunity when he writes of the need for a renewal of philosophy:

It is time for a new departure, and indeed the last decade or two have seen a great broadening of philosophical interests, but as yet no overall unifying direction has emerged from the ferment of ideas. The general difficulties of reviving philosophy are compounded by the nature of the philosophy which went before. First, the philosophy of Wittgenstein, by its own admission, provided little or no firm doctrine against which others can react, and he himself set a pernicious example of technical incompetence in philosophy. Second, the positivism of the 1930 s promulgated a conception of reason which effectively divorced philosophy from the findings of the sciences, the historic roots of culture, and the ends of human life, thus encouraging a facile and purely self-interested form of philosophising. Third, both these factors contributed largely to the divorce between academic philosophy and the general educated public, which in the long run was bound to weaken the position of academic philosophy itself in the world.

Mr Thomas's sermon is his prize-winning essay in the recent Mind competition for a defence of academic philosophy. Under the title 'The Schoolman's Advocate: In Defence of the Academic Pursuit of Philosophy', it was published in Mind in October 1989. The author takes seriously his commitment to defend academic philosophy. Though he himself is described as a 'free-lance philosopher' he is dismissive of what he calls 'do-it-yourself philosophy'. He conceives the philosopher's role as the tenure of an 'office' rather than as a response to a call. He has doubts about doctoral degrees, but is otherwise in favour of the institutionalism and professionalism that philosophy has now suffered or achieved. He notes parallels between philosophy and art, but does not follow them through: would he say of Tolstoy, or of George Eliot or T. $\mathrm{S}$. Eliot, that they lacked the proper training and initiation into their 
professions? One of his personal injunctions to his colleagues is that they should 'dare to be different': 'There has always been something of the maverick about the philosopher, who never feels fully comfortable unless he thinks and acts differently from the herd'. This is all agreeably astringent, but fittingly more reminiscent of an agonisma es to parachrema than of a thing of beauty or a joy for ever.

C. A. J. Coady is a plainer speaker in another sense of the word: his paper 'The Justification of Philosophy', first delivered to a Critical Thinking Conference on The Future of Philosophy at the University of New South Wales, brandishes no epigrams or aphorisms or slogans. Yet much of its undecorated prose amounts to plain speech in Wilde's sense, and he is particularly severe on the present Australian Government and its Education Minister. His essay is less provocative because it is more intricate and accurate in its description of where we are and where we have come from. He recognises that 'philosophy is inevitable', and hence by implication repudiates $\mathrm{Mr}$ Thomas's view of all philosophy as resting upon the foundation of a trained profession. As when Ryle blamed philosophers for the generation of Cartesian confusions about substance, mind and body, we need to ask here how the first philosophers came into being-for good or ill-if there were originally no philosophers but only innocent human beings, speakers and reasoners who had not inherited 'the original philosophical sin' that came to us with language.

Coady warns us, too, that if those who are trained to hold the office or born to answer the call do not fulfil their contract or their destiny, bad work will be offered to fill the gaps in the public need. He tells a horror story about a one-day Government conference for the training of civil servants in 'how to present arguments from data to conclusions in their reports'. It is clear that every continent has the de Bono it deserves. 